\title{
Representações sociais da qualidade de vida no HIV/AIDS: o papel do tempo de diagnóstico
}

\author{
Social representations of quality of life in HIV/AIDS: the role of time since diagnosis \\ Representaciones sociales de la calidad de vida en el VIH/SIDA: el papel del tiempo de \\ diagnóstico
}

\author{
Rodrigo Leite Hipolito'; Denize Cristina de OliveiraII; Antonio Marcos Tosoli Gomes ${ }^{I I I}$; Tadeu Lessa da CostaIV
}

\begin{abstract}
RESUMO: Esta pesquisa teve por objetivo analisar a qualidade de vida e suas representações em momentos distintos do diagnóstico. Estudo qualitativo, descritivo orientado pelo referencial da Teoria das Representações Sociais. Participaram, por meio de entrevista semiestruturada, durante os meses de maio de 2013 a janeiro de 2014, pessoas soropositivas para o Vírus da Imunodeficiência Humana (HIV) cadastradas no Programa de DST/AIDS e Hepatites Virais de um município do Rio de Janeiro, obedecendo à estratificação por tempo de diagnóstico, o que resultou em dois grupos com 20 sujeitos cada. Na análise lexical, operacionalizada pelo software Alceste, a qualidade de vida frente ao diagnóstico emergiu em seu contexto ampliado, identificando cinco categorias. Constatou-se um perfil representacional da qualidade de vida tendente para aspectos positivos e de ressignificação, apoiados nas novas simbologias atribuídas ao objeto AIDS.
\end{abstract}

Palavras-Chave: Qualidade de vida; vírus da imunodeficiência humana; síndrome da imunodeficiência adquirida; enfermagem.

\begin{abstract}
This qualitative, descriptive study, guided by the framework of the Theory of Social Representations, examined quality of life and its representations at different times from diagnosis. Individuals seropositive for human immunodeficiency virus (HIV) and enrolled in the STD/AIDS and Viral Hepatitis Program in a town in Rio de Janeiro State were subject to semistructured interviews between May 2013 and January 2014 and stratified by time since diagnosis. This resulted in two groups of twenty subjects each. In lexical analysis operationalized by Alceste software, quality of life in view of the diagnosis emerged in its broader context, revealing five categories. The representational profile of quality of life was found to tend towards positive aspects and resignification supported by new symbols attributed to the object AIDS.
\end{abstract}

Keywords: Quality of life; human immunodeficiency virus; acquired immunodeficiency syndrome; nursing.

RESUMEN: Esta investigación tuvo como objetivo examinar la calidad de vida y sus representaciones en diferentes momentos del diagnóstico. Se trata de un estudio cualitativo, descriptivo guiado por el marco de la Teoría de las Representaciones Sociales. Participaron, en entrevistas semiestructuradas, durante los meses de mayo de 2013 a enero de 2014, individuos seropositivos para el Virus de la Inmunodeficiencia Humana (VIH) inscritos en el Programa de ETS / SIDA y la Hepatitis Viral en una ciudad de Río de Janeiro - Brasil, obedeciendo al tiempo de diagnóstico, lo que resultó en dos grupos de 20 sujetos cada uno. En el análisis léxical, operacionalizado por el software Alceste, la calidad de vida mediante el diagnóstico surgió en su contexto ampliado, identificando cinco categorías. Se encontró la representación social de la calidad de vida, considerada en sus aspectos positivos y replanteamiento, apoyadas a nuevos símbolos asignados al perfil del objeto SIDA.

Palabras Clave: Calidad de vida; virus de la inmunodeficiencia humana; síndrome de inmunodeficiencia adquirida; enfermería.

\section{INTRODUÇÃO}

Este artigo consiste em um recorte da tese Qualidade de vida das pessoas que convivem com o HIV/AIDS, em um município da Baixada Litorânea, no Estado do Rio de Janeiro desenvolvida no Programa de Pós-Graduação em Enfermagem da Universidade do Estado do Rio de Janeiro.
Compreender a qualidade de vida (QV) de quem vive com o Vírus da Imunodefiência Humana (HIV)/Síndrome da Imunodeficiência Adquirida (AIDS) a partir de esferas objetivas e subjetivas, é um grande desafio, sendo necessário para isso não haver reducionismos perante o tema, pois o que se percebe

IDoutorando em Enfermagem pela Faculdade de Enfermagem da Universidade do Estado do Rio de Janeiro. Professor Assistente da faculdade de Enfermagem da Universidade Federal Fluminense. Rio de Janeiro, Brasil. E-mail: professorrlh@uol.com.br

IIProfessora Titular do Departamento de Fundamentos de Enfermagem e do Programa de Pós-Graduação em Enfermagem da Faculdade de Enfermagem da Universidade do Estado do Rio de Janeiro. Brasil. E-mail: dcouerj@gmail.com

IIIProfessor Titular do Departamento de Enfermagem Médico-Cirúrgica e do Programa de Pós-Graduação em Enfermagem da Faculdade de Enfermagem da Universidade do Estado do Rio de Janeiro. Brasil. E-mail: mtosoli@gmail.com

${ }^{I V}$ Professor Adjunto no Curso de Enfermagem e Obstetrícia da Universidade Federal do Rio de Janeiro. Macaé, Rio de Janeiro, Brasil. E-mail: tadeulessa@yahoo.com.br 
são inter-relações constantes entre os elementos que compõem esse universo ${ }^{1}$. $\mathrm{O}$ aumento da sobrevivência das pessoas que vivem com o HIV/AIDS (PVHA) leva a novas fontes de incertezas provocadas pela renegociação que os mesmos necessitam fazer com relação aos seus sentimentos de esperança e orientação para o futuro, aos seus papéis sociais e identidades, às suas relações interpessoais e à sua $\mathrm{QV}^{2}$.

A Organização Mundial de Saúde (OMS) define QV como uma

percepção que o indivíduo tem em relação à sua posição na vida, cultura e sistema de valores nos quais ele está inserido, e também em relação aos seus objetivos, expectativas, padrões e preocupações $^{3: 25}$.

Pode-se dizer que a infecção afeta vários aspectos da QV das PVHA, influenciando os domínios físico, psicológico, nível de independência, relações sociais, meio ambiente e espiritualidade, religiosidade e crenças pessoais ${ }^{4}$. Contudo, percebe-se que os indivíduos encontram meios para se adaptar e aprender a conviver com a mesma contribuindo para que existam mudanças na forma de interpretá-la ${ }^{5}$.

Estudar a representação social (RS) da QV neste grupo poderá fornecer conhecimento da configuração simbólica do fenômeno e dos modos de ver e pensar o HIV/AIDS, relevante para as diversas discussões que vem sendo feitas no campo da saúde na atualidade. Considerando os argumentos expostos, admite-se a hipótese de que o tempo de diagnóstico e convívio com o HIV/AIDS carreiam diferenças nos conteúdos das RS da QV.

Frente a essas observações, foi estabelecido como objetivo deste estudo-analisar a QV e suas representações em momentos distintos de diagnóstico, entre PVHA, em um município da baixada litorânea do estado do Rio de Janeiro.

\section{Referencial Teórico-MetodolóGico}

Este estudo caracterizou-se como exploratório, descritivo e qualitativo. A análise foi apoiada na Teoria das Representações Sociais (TRS) ${ }^{6}$, utilizando-se a abordagem processual ${ }^{7}$, haja vista que esta enfatiza o processo de constituição das representações, embora também afirme a importância de seu produto, qual seja, os conteúdos ${ }^{8}$.

Foram investigadas as pessoas soropositivas para o HIV que atendiam aos seguintes critérios de inclusão: igual ou maior de 18 anos; cadastradas no Programa de Doenças Sexualmente Transmissíveis (DSTs), AIDS e Hepatites Virais do município de Rio das Ostras/RJ, que possuíssem condições clínicas e psicológicas para responderem aos instrumentos de pesquisa. Isso foi feito durante o período compreendido entre os meses de maio de 2013 a janeiro de 2014.
Definiu-se para este estudo uma amostragem não-probabilística por conveniência de 20 pessoas com tempo de diagnóstico compreendido até os 6 meses e 20 pessoas com tempo de diagnóstico superior aos 6 meses. Os sujeitos foram convidados a participar da pesquisa, enquanto aguardavam a consulta médica na sala de espera, levando-se em consideração o tempo de diagnóstico, algo que era revelado logo após o aceite em fazer parte do estudo. Na participação dos sujeitos, observouse a Resolução no 466/2012 do Conselho Nacional de Saúde (CNS) e o estudo foi aprovado pelo Comitê de Ética em Pesquisa da Universidade do Estado do Rio de Janeiro (UERJ), $\mathrm{n}^{\circ}$ 073/2012 e código de protocolo $\mathrm{n}^{\circ}$ 066.3.2012. Os participantes leram e assinaram o Termo de Consentimento Livre e Esclarecido (TCLE).

A coleta de dados foi realizada por meio de entrevistas, com o auxílio de dois instrumentos: um questionário estruturado de caracterização dos sujeitos, composto por variáveis socioeconômicas, e um roteiro semiestruturado que investigou a compreensão da QV, identificando conceitos e diferentes concepções das PVHA, assim como, os sentimentos, metáforas, imagens e valores existentes. Pretendeu-se abordar o modo como os sujeitos concebem os impactos da soropositividade sobre a QV, desde o momento do diagnóstico até a atual fase da doença. $O$ registro se deu pela gravação em áudio MP3 e posteriormente a sua transcrição. Os sujeitos foram codificados com a letra (E) em ordem numérica.

Para análise dos dados, utilizou-se o software ALCESTE 4.10 que tem a finalidade de realizar, automaticamente, a análise lexical de conteúdo por meio de técnicas quantitativas de tratamento de dados textuais. Essa técnica, além de descrever as leis de distribuição do vocabulário, permite o estudo dos tipos de representação presentes no texto. Nessa perspectiva, distancia-se de modos tradicionais de distribuição de palavras pelo emprego da abordagem estatística que compreende a regularidade da distribuição do vocábulo nas unidades de contexto elementares (UCE) ${ }^{9}$.

O material transcrito foi padronizado constituindo um corpus de análise inserido no software no formato de texto simples ${ }^{9}$. Variáveis socioeconômicas foram codificadas, de modo a inseri-las no corpus de análise. O software realizou o tratamento do corpus com sua divisão em UCE, bem como em classes compreendendo as mesmas, de acordo com as formas lexicais que as compuseram ${ }^{9}$.

Após a clivagem do corpus, 741 UCE, representando $64 \%$ de aproveitamento, foram inseridas nas classes em que foi dividido o corpus por sucessivas partições binárias na classificação descendente hierárquica $(\mathrm{CDH})$, o conjunto das entrevistas dos sujeitos. No presente estudo, portanto, emergiram cinco classes, as quais comportam conteúdos das RS da QV do grupo que vive com HIV/AIDS. 


\section{Resultados e Discussão}

O grupo estudado caracterizou-se como tendo perfil de vulnerabilidade social compatível com o de outras investigações entre PVHA no Brasil. Foi composto igualitariamente entre os sexos, com tempo de diagnóstico menor que 4 anos (68\%), em uso de terapia antirretroviral (TARV) (74\%) e tempo de uso de TARV menor que 4 anos (52\%), de orientação religiosa evangélica (36\%), sendo solteiros (53\%), com média de idade dos 37 anos, portadores de 2 ou 3 filhos (35\%), residentes em sua maioria no próprio município de tratamento (89\%), compartilhando a moradia com até 4 pessoas (76\%) da família (82\%), apresentando baixo nível de escolaridade (48\%), exercendo alguma atividade empregatícia (65\%), na faixa predominante de renda familiar compreendida entre $\mathrm{R} \$ 701,00$ a $\mathrm{R} \$$ 1400,00 (33\%) e possuindo como principal fonte de informações a respeito do HIV/AIDS, o próprio local de tratamento $(48 \%)$.

O detalhamento das classes geradas pelo software ALCESTE, referindo-se aos conteúdos das RS da QV, foi feito pela ordem sucessiva de constituição temática, conforme a Figura 1.

\section{Classe 5: Transmissão e prevenção do HIV/ AIDS e a QV}

A classe 5 possui 167 UCE (22\%) sendo a primeira que surgiu após a divisão binária do corpus. A referida classe é a segunda de maior peso dentro da $\mathrm{CDH}$ e apresentou como categorias de variáveis de maior associação estatística, pessoas que não usam antirretroviral (ARV) e o tempo de diagnóstico. Em destaque a variável tempo de diagnóstico menor que seis meses, apresentou-se entre as de maior associação estatística na classe $(\times 2=16)$, revelando que os sujeitos estratificados nessa categoria apresentaram forte contribuição para os conteúdos representacionais associados aos meios de transmissão do HIV.

As formas reduzidas (palavras reduzidas aos seus radicais) com maiores valores de associação estatística a classe (no teste de qui-quadrado- $\mathrm{x}^{2}$ ), foram: relação sexual, preservativo, sangue, transmit, transmissão, transfus, origem, contamin.

Entretanto, os conteúdos representacionais situados na lógica da prevenção apresentaram-se como insuficientes para uma parte do grupo considerando as suas consequências individuais e coletivas. As

\section{A QUALIDADE DE VIDA E O HIV/AIDS}

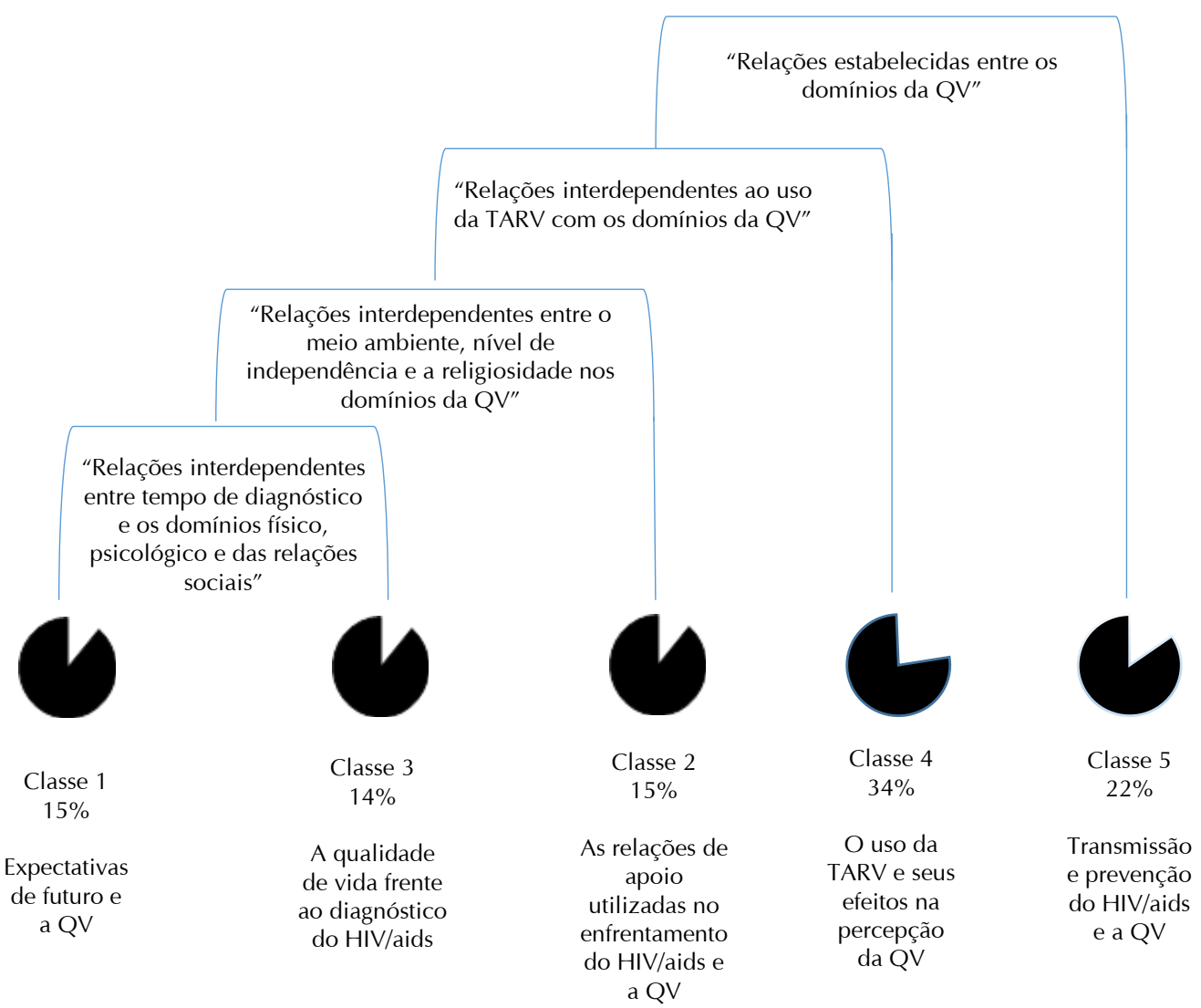

FIGURA 1: Dendograma de distribuição das classes geradas pelo software ALCESTE. Rio das Ostras, RJ, 2014. 
mulheres perceberam-se como afetadas, existindo fatores socioculturais que interfeririam nas relações de poder quanto à decisão da prática do sexo seguro. Como consequência dessas decisões, algumas dificuldades, como o sentimento de culpa, emergiram de seus conteúdos psicossociais, revelando que por vezes os modos de transmissão possuem razões mais sociais do que individuais ${ }^{10}$. As UCEs posteriores exemplificam os conteúdos da classe:

As formas de transmissão do HIV/AIDS são: sexualmente, pela seringa, transfusão de sangue, mãe para filho na gravidez e através de cortes. (E14)

Um dia o meu esposo falou que era para eu confiar nele e não usar mais o preservativo, eu confiei nele e fiquei sem me prevenir. (E4)

\section{Classe 4: $\mathrm{O}$ uso da TARV e seus efeitos na percepção da QV}

A classe 4 possui 239 UCE (34\%) sendo considerada a de maior peso na CHD. As categorias de variáveis com maior associação estatística foram: sexo feminino e renda pessoal entre 3,1 a 5 salários mínimos. As formas reduzidas associadas foram: antirretrovir, descobri, tratamento, hospit, alimente, consult, remédio, hora.

Percebeu-se nessa classe que a representação da QV foi associada não apenas ao uso da TARV, mas, também ao tratamento em uma concepção ampliada, envolvendo várias dimensões do HIV/AIDS e da vida. As associações mais positivas da QV foram caracterizadas pelo entendimento da necessidade de uma readaptação aos novos hábitos cotidianos e a manutenção de comportamentos saudáveis para a vida. De forma complementar, mas antagônica às necessidades percebidas, as maiores dificuldades relatadas pelos participantes foram associadas à QV pior, sendo representadas pelos efeitos colaterais farmacológicos, a rotina imposta por horários dos medicamentos e problemas com a autoestima.

O uso da TARV é percebido como provocador de consequências positivas, uma vez que está associada a melhores perspectivas de vida, em detrimento da ideia de morte advinda do diagnóstico da doença. Entretanto, enfatiza-se que os efeitos colaterais consistem em fator relevante na dinâmica de uso e adesão à TARV, especialmente, no início do tratamento ${ }^{4}$.

Não me sinto incapaz, não me sinto doente. O ARV é minha vida, porque sem ele eu não estaria aqui. A única interferência que o $\mathrm{ARV}$ possui na minha $\mathrm{QV}$ é que existe um comprimido que me faz mal, o último do dia, porque eu tomo três comprimidos por dia. (E2)

No dia em que eu recebi o meu diagnostico HIV/AIDS eu quis me matar, mas, tive ânimo porque existia um tratamento, um coquetel de $A R V$ que eu poderia tomar e ficar boa. (E5)
A adesão ao tratamento assume, simbólica e concretamente, a luta pela vida, mobilizando um sentido para viver ${ }^{11}$. Desse modo, os significados que os sujeitos atribuem aos ARV diante do HIV/AIDS pela necessidade da adoção de novas práticas de vida, em situação de confronto com o não querer fazer uso, ensejado pelas inúmeras repercussões que poderiam advir, compreendem uma das formas de apreensão da TRS. Essa apreensão se embasa no sentido que os sujeitos usuários da TARV, atribuem ao novo contexto da vida imposto pela condição atual, refletindo na RS da QV.

\section{Classe 2: Relações de apoio no enfrenta- mento do HIV/AIDS e a QV}

A classe 2 possui 114 UCE (15\%) e apresentou como categorias de variáveis com maior associação estatística: pessoas em uso da TARV entre dois e cinco anos $(\mathrm{x} 2=16)$ e tempo de diagnóstico entre dois a cinco anos. As formas reduzidas associadas foram: programa dst aids, profissionais da sa, relig, evangel, fe, ótimo, catol, igreja, suport, espirit, esperança.

Em concordância a outros estudos, houve destaque aos conteúdos representacionais da QV no âmbito do setor saúde de uma forma abrangente ${ }^{4}$. $\mathrm{O}$ perfil de convívio estabelecido entre os sujeitos e o Programa, acrescido de uma resposta satisfatória frente às políticas locais existentes, revelou um conteúdo representacional da QV, positivo e significativo.

A minha relação com os profissionais da saúde no Programa DST AIDS é ótima e isso é importante na QV. Eles são ótimos, atenciosos e eu realmente não tenho do que reclamar da qualidade do atendimento, pelo menos aqui comigo não. (E23)

Os aspectos relacionados a hábitos e estilos de vida, estresse e estratégias de coping e/ou enfrentamento e apoio social estão implicados no processo saúde-doença ${ }^{12}$. O diagnóstico contribuiu para reflexões e questionamentos, que se tornaram um caminho para o encontro de um sentido para a vida e, consequentemente, o cultivo da espiritualidade.

Eu acho que sem a religião, hoje eu estaria morto, porque quando eu descobri que eu estava com o HIV/ AIDS, se deus não tivesse enviado essa mulher da igreja para me ajudar, não sei como eu estaria hoje. (E2)

Os posicionamentos relacionados à espiritualidade podem ser destacados como uma das variáveis presentes na capacidade de resiliência e proteção da saúde. Desta forma, percebe-se que a dimensão espiritual identificada esteve presente nas construções de significados da QV para o grupo em questão, integrados nos modelos explicativos do adoecimento e às formas de enfrentamento da doença.

Assim, o fato de serem portadores do vírus HIV com suas repercussões psicobiológicas, não implicaria 
que os sujeitos pudessem considerar a partir de sua forma de conhecimento elaborado, valores pessoais e crenças compartilhados, uma boa QV e alto grau de satisfação com a saúde, contribuindo para a construção de uma realidade comum ao conjunto social? ${ }^{7}$.

\section{Classe 3: A qualidade de vida frente ao diag- nóstico do HIV/AIDS}

A classe 3 possui 106 UCE (14\%) e representou o grupo que mais concentrou a temática da QV na análise. A categoria de variável com maior associação estatística foi sexo masculino. Percebe-se a presença das seguintes formas reduzidas associadas: qualidade de vida, diagnostico, normal, preocup, negativo, HIV/ AIDS, tranquila, vida, sexualidade.

Os participantes dessa classe expressaram a relação da QV com o diagnóstico do HIV/AIDS. Tal relação foi revelada pela percepção do cuidado consigo mediante o diagnóstico e com a saúde, assim como, foram expostos sentimentos relacionados às mudanças impostas pelo contexto das relações e também os reflexos no campo da sexualidade. $\mathrm{O}$ autocuidado evidenciou-se, principalmente, na mudança de hábitos e atividades diárias após o diagnóstico, na intenção de proporcionarem a si mesmo bem estar físico, embora o aspecto emocional também não tenha sido descartado. Tal posicionamento sugere uma característica resultante da ressignificação do processo de adoecimento, manifestando-se em sentir-se bem, mesmo perante a doença, podendo ser traduzida numa sensação de crescimento pessoal e aprimoramento emocional.

Não acho que o diagnostico HIV/AIDS terá impacto na minha QV, pelo contrário, isso vai poder melhorar mais ainda a minha QV ao longo dos anos porque eu irei me cuidar mais. (E 25)

Pode-se dizer que a QV no contexto da soropositividade, perpassa por uma combinação de fatores individuais e sociais, que podem advir da família, dos amigos e da própria religião, resultando em uma interpretação que poderá ser mais positiva ou menos positiva da QV, o que dependerá também de atributos individuais. Percepções semelhantes foram encontradas em outros estudos ${ }^{13}$.

A minha QV após o HIV/AIDS boa porque valorizo a paz, apesar dessas coisas negativas, eu procuro pensar coisas nas coisas boas. Viver! Eu penso assim. Estou vivendo da mesma forma que eu vivia antes de saber do meu HIV/AIDS, não deixei me afetar. (E40)

A preocupação com a revelação do diagnóstico presente nos depoimentos, afeta negativamente a QV em função do medo de tornar público uma condição que pode predispor ao preconceito e estigmatização. Entretanto, quando o apoio dos familiares e amigos está presente, essa adaptação a nova existência tornase mais fácil de ser encarada e os reflexos na melhoria da QV ficam mais evidentes. Observou-se que alguns sujeitos apresentaram tendência a naturalizar o viver com o HIV e tais construções cognitivas não foram percebidas como uma fuga da situação, mas como adaptação e aceitação da soropositividade, conforme observado em outras investigações ${ }^{10}$.

Identificou-se que a sexualidade representa um papel importante na vida dessas pessoas e possui uma relação com a QV, pois afeta diversas dimensões, desde questões relacionadas à disfunção sexual pelo uso dos antirretrovirais, interferência na autoestima e até a perda de libido, dentre outros. De acordo com os dados, a sexualidade é um importante elemento com o qual as PVHA se confrontam ${ }^{14}$.

Minha QV sofreu impacto na questão física, hoje fico cansado, perdi um pouco da disposição que eu tinha antes do HIV/AIDS. Isso, aquela disposição de você ir mais além durante o sexo, você vai mas tem que voltar. O HIV/AIDS muda nosso campo da sexualidade, muda muito. (E13)

\section{Classe 1: Expectativas de futuro e a QV}

A classe 1 possui 115 UCE (15\%) do corpus analisado, representando a terceira classe em número de UCE. A categoria de variável com maior associação estatística foi tempo de uso da TARV entre 7 meses a 1 ano e 11 meses. Nota-se a presença das seguintes formas reduzidas: quer, pior, futuro, consegu, filhos, vou, estud, mort, preconceito, família, sozinh, trabalh, alegr, coleg e pais.

Os participantes do estudo puderam expressar suas expectativas quanto ao futuro dentro do atual contexto vivenciado, relacionando tanto as circunstâncias que envolvem à família, como aquelas que dizem respeito às relações com o trabalho e a outras situações de vida em um cenário social mais ampliado. Identificou-se um discurso positivo e de esperança depositado na vida futura. A possibilidade de conceber boas expectativas e desfrutar de uma boa saúde, semelhante aos não portadores do vírus, se traduz em melhor aceitação da condição de soropositividade e maior adaptação, o que acaba por refletir na QV.

Por conseguinte, a importância da vida no contexto do HIV/AIDS é encontrada, por muitos participantes, por meio dos filhos. A pessoa com HIV também vê nos filhos um motivo para continuar a viver, à medida que sente a necessidade de cuidar deles e acompanhá-los no seu crescimento, constituindo-se, portanto, uma fonte de força para viver ${ }^{13}$.

Para o futuro, eu peço que Deus me dê saúde para ver os meus netinhos, a felicidade dos meus três filhos e dos meus dois netinhos. (E5)

Todavia, dentre os entrevistados observam-se UCE que expressam sentimentos antagônicos, de insatisfação com a condição atual e dificuldades em pro- 
jetar sonhos a longo prazo. Observa-se que a QV para o grupo não está relacionada apenas à possibilidade de vida mais longa, pois viver nessa condição ainda representa se deparar com situações de discriminação, abandono, segregação, estigmatização e ruptura das relações afetivas. Diante desse panorama, enfrentar a doença torna-se complexo e, como consequência, a QV pode ser afetada ${ }^{15}$.

Enfim, eu não sei se o meu sentimento de agora é um estado de permanência, mas nesse momento eu não espero nada do futuro. (E38)

Uma característica encontrada em parte do grupo, e comum a tantos outros em situações semelhantes, é o afastamento da casa e dos familiares. Os relatos de preocupação em serem apontados pelos familiares, apresenta correlação com a ancoragem da AIDS na corrupção moral? ${ }^{7}$ A associação feita por alguns dos entrevistados, referindo que a sua QV poderia ser melhor, se não existisse o preconceito, remete à ideia das minorias que se sentem desvalorizadas perante uma maioria dentro de uma sociedade, o que a distinguiria e a marcaria em sua assimetria ${ }^{16}$.

Acabar com o preconceito melhoraria a QV de quem vive com HIV/AIDS para eu poder voltar para perto da minha família, porque eu penso muito em voltar, mas eu penso muito no ser apontado (E2)

As preocupações relacionadas ao cenário do trabalho também estiveram presentes na análise dos discursos podendo se propagar em dois eixos: um de caráter mais positivo, que favorece uma melhor QV ao propiciar melhores condições financeiras e oferecer estabilidade, credibilidade e ocupação psicossocial; e um outro eixo de caráter mais negativo, no qual o trabalho é associado à diminuição e ou perda da capacidade $^{17}$.

\section{Conclusão}

Os resultados caracterizaram-se pela transição de significados negativos para positivos associados ao HIV/AIDS, com a introdução da possibilidade de convivência com a doença, assim como os seus impactos para a QV com o afastamento da morte iminente.

Quanto à hipótese de interferência temporal na RS da QV, conclui-se que emergiram cognições alusivas à melhor QV em ambos os grupos. No entanto, considerando que o nível de conhecimento proveniente do universo reificado pode contribuir para repensar estigmas, remover mitos e melhorar a aderência ao tratamento, destaca-se que o grupo com menor tempo de vivência com o vírus apresentou conteúdos concernentes à transmissão que podem influenciar a forma de pensar a QV no contexto do HIV/AIDS. Do mesmo modo, os sujeitos com maior tempo de diagnóstico apresentaram conteúdos representacionais ancorados na religiosidade, o que contribuiria para a ressignificação da doença e reorientação de expectativas e projetos de vida.

Sendo assim, a condição da vivência com a soropositividade, por si só, representa uma reelaboração de vários processos, em especial aqueles condicionantes à manutenção de uma boa saúde mental e que, em conjunto com uma rede de apoio psicossocial e espiritual desde o momento da descoberta do diagnóstico, contribuiria marcadamente para a melhoria da QV.

Observaram-se nesses resultados conteúdos cognitivos apontados como centrais na RS da AIDS como em outros estudos da TRS e HIV/AIDS, a exemplo do preconceito, família, profissionais da saúde e os ARV, por conseguinte, tais considerações reforçam a ideia de que as RS da QV sejam não autônomas em relação à RS da AIDS.

Embora não possa ser possível generalizar os achados deste estudo para outras populações e regiões do país, eles forneceram uma visão geral sobre a RS da QV e a sua relação com os aspectos socioeconômicos e clínicos das PVHA, num contexto de interiorização, em um município do Estado do Rio de Janeiro. Além disso, podem oferecer informações úteis para subsidiar as políticas de saúde da região.

\section{REFERÊNCIAS}

1.Almeida MAB, Gutierrez GL, Marques R. Qualidade de vida: definição, conceitos e interfaces com outras áreas, de pesquisa. São Paulo: Escola de Artes, Ciências e Humanidades; 2012.

2.Castanha AR, Coutinho MPL, Saldanha AAW, Ribeiro CG. Aspectos psicossociais da vivência da soropositividade ao HIV nos dias atuais. PSICO. 2006; 37 (1):47-56. 3.Fleck MPA. Problemas conceituais em qualidade de vida. In: Fleck MPA, organizador. A avaliação da qualidade de vida: guia para profissionais da saúde. Porto Alegre (RS): Artmed; 2008. p.19-28.

4.Costa TLD. Representações sociais do HIV/Aids e da qualidade de vida: um estudo entre pessoas que vivem com o agravo em contexto de interiorização [tese de doutorado]. Rio de Janeiro: Universidade do Estado do Rio de Janeiro; 2012.

5.Meirelles BHS, Silva DMGV, Vieira FMA, Souza SS, Coelho IZ, Batista R. Percepções da qualidade de vida de pessoas com HIV/Aids. Rev RENE. 2010; 11(3):68-76. 6.Moscovici S. O fenômeno das representações sociais. In: Moscovici S. Representações sociais: investigações em psicologia social. Petrópolis (RJ): Vozes; 2003 - p.29-109. 7.Jodelet D. Representações sociais: um domínio em expansão. In: Jodelet D, organizadora. As representações sociais. Rio de Janeiro: EDUERJ; 2001. p.17-44.

8.Sá CP. A construção do objeto de pesquisa em representações sociais. Rio de Janeiro: EdUERJ; 1998.

9.Oliveira DC, Gomes AMT, Marques SC. Análise estatística de dados textuais na pesquisa das representações sociais: alguns princípios e uma aplicação ao campo da saúde. 
In: Menin MSS, Shimizu AM, organizadores. Experiência e representação social: questões teóricas e metodológicas. São Paulo: Casa do Psicólogo; 2005. p.157-200.

10.Gomes AMT, Silva EMP, Oliveira DC. Social representations of AIDS and their quotidian interfaces for people living with HIV. Rev Latino-Am Enfermagem. 2011; 19:485-92.

11.Espírito Santo CC, Gomes AMT, Oliveira DC, Marques SC. Adesão ao tratamento antirretroviral e a espiritualidade de pessoas com HIV/AIDS: estudo de representações sociais. Rev enferm UERJ. 2014; 21:458-63. 12.Seidl EMF, Zannon C, Tróccoli BT. Pessoas vivendo com HIV/AIDS: enfrentamento, suporte social e qualidade de vida. Psicologia: Reflexão e critica. 2005; 18:188-95.

13.Espírito Santo CC, Gomes AMT, Oliveira DC. A espiritualidade de pessoas com HIV/AIDS: um estudo de representações sociais. Rev Enf Ref. 2013; 10:15-24. 14.Gonçalves TR, Carvalho FT, Faria ER, Goldim JR, Piccinini CA. Vida reprodutiva de pessoas vivendo com HIV/ AIDS: revisando a literatura. Psicol soc. 2009; 21:223-32. 15.Galvão MTG, Cerqueira ATAR, Marcondes-Machado J. Avaliação da qualidade de vida de mulheres com HIV/AIDS através do HAT- QoL. Cad Saúde Pública. 2004; 20:430-7. 16.Moscovici S. Preconceito e representações sociais. In: Almeida AMO, Jodelet D, organizadores. Representações sociais: interdisciplinaridade e diversidade de paradigmas. Brasília(DF): Thesaurus; 2009. p.17-34.

17.Castanha AR, Coutinho MPL, Saldanha AAW, Ribeiro CG. Avaliação da qualidade de vida em soropositivos para o HIV. Estud psicol. 2007; 24(1):23-31. 